\title{
INFECCIÓN LETAL POR ADENOVIRUS. PRESENTACIÓN DE UN CASO LETHAL INFECTION FOR ADENOVIRUS. CASE REPORT
}

\author{
Dr. Yuri Zuleta M. ${ }^{1}$, Dra. Pamela Martínez B. ${ }^{2}$, Dra. María Cristina Patarroyo G. ${ }^{3}$, Dra. Marcela Concha V. ${ }^{3}$, Dr. Víctor Monreal E ${ }^{3}$. \\ 1. Pediatra Intensivista. Unidad de Paciente Crítico Pediátrico. Clínica Indisa y Hospital Roberto del Río. \\ 2. Pediatra especialista en Enfermedades Respiratorias Pediátricas. Clínica Indisa y Hospital de La Florida. \\ 3. Pediatra Intensivista. Unidad de Pacientes Crítico Pediátrico. Clínica Indisa.
}

\begin{abstract}
Adenovirus (ADV) can cause serious, localized or disseminated, sometimes lethal disease. There is no specific treatment, only support management according to requirements and severity of disease. Extracorporeal membrane oxygenation (ECM0) has been used in severe ADV infection. Cidofovir has been reported as a therapeutic option. This case reports a lethal case of ADV respiratory infection despite the treatment with cidofovir an ECMO.
\end{abstract}

Keywords: Adenovirus Infections Human, Extracorporeal Membrane 0xygenation, viral load.

\section{RESUMEN}

El adenovirus (ADV) puede causar infección respiratoria grave, localizada o diseminada y letal en pacientes susceptibles. No existe terapia específica, solo de soporte según requerimientos y gravedad. En este sentido el manejo con oxigenación por membrana extracorpórea (ECMO) ha sido utilizado en niños con infección grave por ADV. Si bien no existe terapia específica actual se ha reportado uso de cidofovir que ha ganado espacio como posibilidad terapéutica en caso de enfermedad grave. Se presenta el caso clínico de un paciente que cursó con infección letal por ADV a pesar del tratamiento de soporte con ECMO y el tratamiento con cidofovir.

Palabras clave: Infecciones por Adenovirus Humanos, 0xigenación por Membrana Extracorporea, carga viral.

El adenovirus (ADV) tiene al menos 55 serotipos implicados en patología en humanos. Puede causar infección a cualquier edad, pero más del $80 \%$ se presentan en menores de 5 años. Típicamente, genera enfermedad autolimitada respiratoria o enteral en pacientes inmunocompetentes, pero puede ocasionar enfermedad grave localizada o diseminada, incluso letal, especialmente en neonatos, lactantes menores y niños transplantados de células hematopoyéticas o de órganos sólidos $(1,2,3)$.

Los serotipos $3,7,7$ a y 21 son los más relacionados con infecciones respiratorias bajas, enfermedad sistémica, y con secuelas pulmonares (4).

No se cuenta con terapia específica, en enfermedades graves se intenta dar soporte de acuerdo a los requerimientos. El manejo con oxigenación por membrana extracorpórea (ECMO) ha sido reportado como parte del soporte en infecciones graves por

\section{Correspondencia:}

Dra. Pamela Martínez

Clínica Indisa. Av Santa Maria 1810 Providencia.

(+569) 23625555

pa.martinezb@gmail.com adenovirus, siendo el tercer virus en frecuencia entre pacientes pediátricos que requieren ECMO, pero con la peor sobrevida $(25 \%)(1)$.

Se han probado fármacos como ribavirina 0 inmunoglobulina endovenosa en pacientes inmunosuprimidos, sin éxito consistente. También se reporta uso de cidofovir, que es un análogo de la cistidina y el difosfonato, con amplio espectro de acción in vitro e in vivo contra una gran variedad de virus, incluyendo los virus herpes y los adenovirus. Una vez internalizado por endocitosis, ejerce su acción como inhibidor competitivo y sustrato alternativo en la reacción de la DNA polimerasa viral, lo que le ha permitido ganar un espacio como terapia en pacientes con infecciones graves por ADV(5). El mayor efecto adverso del Cidofovir es la nefrotoxicidad. La hiperhidratacion, y la administración conjunta de probenecid, un ácido orgánico que actúa como competidor del Cidofovir para el transportador, tienen un efecto nefroprotector(6). Su eficacia ha sido limitada, manteniéndose una mortalidad elevada en Ios pacientes con infección diseminada por adenovirus (5)(6).

Se presenta el caso clínico de un paciente que cursó con infección letal por ADV a pesar del soporte con ECMO y el tratamiento con cidofovir. 


\section{CASO CLÍNICO}

Paciente masculino de 7 meses, prematuro de 31 semanas, sin displasia broncopulmonar diagnosticada. Hospitalizado por dificultad respiratoria, fiebre y decaimiento. Con apoyo de oxigenoterapia hasta $1 \mathrm{~L} / \mathrm{min}$ que se logra suspender al $6^{\circ}$ día, sin embargo, ese día presenta fiebre y dificultad respiratoria. En exámenes destacan: leucocitosis de 43000 con desviación izquierda, PCR: 63 mg/L y radiografía torácica con condensación en lóbulo superior derecho e inferior izquierdo (no se cuenta con imagen). Se inician antibióticos (ceftriaxona y cloxacilina), sin mejoría. Con el antecedente de haber sido contacto de ADV intrahospitalario se realiza PCR ADV que resulta positiva. Evoluciona grave con síndrome de distres respiratorio agudo (SDRA) por lo que es trasladado a unidad de paciente crítico donde se intuba y conecta a ventilación mecánica convencional. Evoluciona con acidosis respiratoria e hipoxemia y se decide paso a ventilación de alta frecuencia (VAFO), con mala respuesta (índice de oxigenación (I0) de 33,7) solicitándose traslado aéreo a nuestra unidad para eventual conexión a ECMO. Ingresa con hipoxemia severa refractaria a VMC, VAFO y óxido nítrico inhalado (iNO) (Figura 1) por lo que se conecta a ECMO veno arterial (V-A). Se mantiene con esquema antibiótico empírico con vancomicina meropenem. Durante manejo en ECMO se apoya con terapia de reemplazo renal contínua (TRRC). Hemocultivos y cultivos de secreción endotraqueal fueron negativos. Se cuantifica carga viral de ADV con más de 20 millones de copias. Destaca además ausencia (recuento 0) de linfocitos B y linfocitos natural killer. Se decidió uso de Cidofovir, completando 3 dosis, asociado a probenecid e hiperhidratación. Desde primera dosis se observa caída de la carga viral pero sin negativizar. Presenta injuria renal aguda secundaria a cidofovir manteniendo TRRC. Se logra retirar ECMO a los 16 días a VMC con parámetros considerados protectores, pero evoluciona con progresión de daño pulmonar, falla multiorgánica, nuevamente a falla respiratoria catastrófica a pesar de VMC, VAFO e iNO. Hemodinámicamente inestable con apoyo de drogas vasoactivas, TRRC y antibióticos de amplio espectro, presenta 2 paros cardiorrespiratorios que responden a reanimación. Evoluciona muy lábil e inestable con acidosis respiratoria y metabólica refractaria a múltiples cambios en estrategias ventilatorias, finalmente presenta asistolia y fallece.

\section{DISCUSIÓN}

Existe documentada resistencia en el mundo a conectar a ECMO a pacientes con enfermedad grave por ADV, por su elevada mortalidad con o sin soporte ECMO, falta de tratamiento etiológico efectivo y su asociación con falla multiorgánica (7). Sin embargo se postula que la combinación de ECMO y TRRC podría favorecer la evolución del SDRA asociado a la enfermedad por ADV (8). Hay reporte de casos de sobrevida de pacientes manejados en ECMO y con cidofovir; aunque la experiencia nacional ha mostrado mal pronóstico aún con respuesta documentada al antiviral (9). En este sentido nuestro caso presenta algunas aristas exclusivas. No se canuló en ignorancia de su etiología (ADV confirmado) por lo que se intentó extremar su manejo pre ECMO. Se confirmó una carga viral inusualmente alta de inicio (> a 20 millones de copias, "inusual" aun con lo inusual que es objetivar esta carga), y si bien respondió a cidofovir, la carga viral nunca se negativizó (con 3 "tandas" de dosis de cidofovir), lo que si se ha observado en otros casos, aunque no necesariamente con mejor resultado final.

La falla renal secundaria al fármaco podría ser influido por otro hallazgo inusual, un recuento de linfocitos especificos de cero. No sabremos si esta es una condición previa del menor o secundaria a su patología y manejo.

Debido a que la enfermedad invasiva grave por ADV tiene mal pronóstico de sobrevida y son pocos casos, creemos que sería muy relevante compartir las experiencias de los distintos centros. En nuestra opinión se debería seguir ofreciendo ECM0, TRRC y antiviral a estos pacientes, quizás con más precocidad, sobre todo si no hay inmunodeficiencias y con el mejor manejo que puede otorgar la experiencia compartida, antes de determinar que esta patología excluye una alternativa terapéutica que es costosa en lo material y humano.

Figura 1. Neumotórax izquierdo con eversión de hemidiafragma. Extensos focos de condensación en lóbulo superior derecho y lóbulo inferior izquierdo con broncograma aéreo.

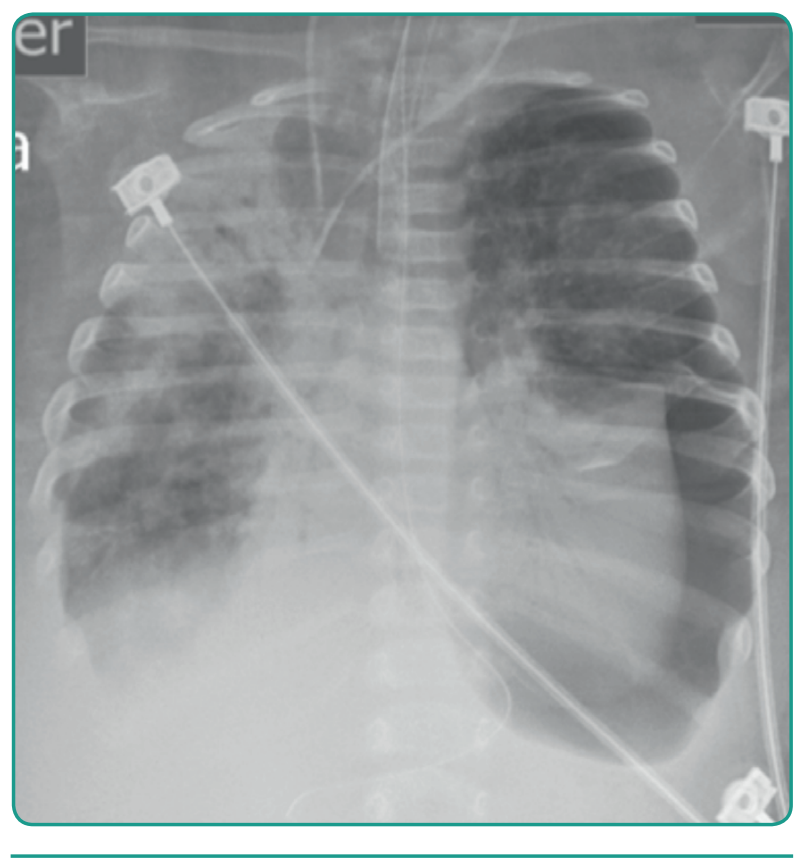

Los autores declaran no presentar conflicto de intereses. 


\section{REFERENCIAS}

1. Prodhan, $P$, Bhutta A, Gossett J, Stroud M, Rycus P, Bratton $S$, Fiser R Extracorporeal membrane oxygenation support among children with adenovirus infection: a review of the Extracorporeal Life Support Organization registry. ASAIO J. 2014 60(1):49-56

2. Ronchi A, Doem C, Brock E, Pugni L, Sanchez P. Neonatal Adenoviral Infection: A Seventeen Year Experience and Review of the Literature. The Journal of Pediatrics. 2014;164:529-35.

3. Ka-Ho Hung and Lung-Huang Lin. Adenovirus Pneumonia Complicated With Acute Respiratory Distress Syndrome. A case report. Medicine 2015; 94 (20): e 776.

4. Carter B, Karpen S; Quiros-Tejeira R, Chang I, Clark B, Demmler G, Heslop H, Scott J, p Seu P, Goss J. Intravenous cidofovir therapy for disseminated adenovirus in a pediatric liver transplant recipient. Transplantation 2002, 74(7):1050-1052.

5. Caruso Brown, A., Cohen, M, Tong, S., Braverman, R., Rooney, J., Giller, R., \& Levin, M. Pharmacokinetics and safety of intravenous cidofovir for life-threatening viral infections in pediatric hematopoietic stem cell transplant recipients. Antimicrobial agents and chemotherapy 2015;
59(7), 3718-25.

6. Vora S, Brothers A, Englund J. Renal Toxicity in Pediatric Patients Receiving Cidofovir for the Treatment of Adenovirus Infection. Journal of the Pediatric Infectious Diseases Society 2017, 6 (4): 399-402

7. 7. Allibhai $T$, Spinella $P$, Meyer $M_{\text {,, Hall B., Kofos }}$ D, DiGeronimo R. Survival after prolonged pediatric extracorporeal membrane oxygenation support for adenoviral pneumonia. Journal of Pediatric Surgery 2008 43, E9-E11

8. Ha, S. O., Kim, H. S., Park, S., Jung, K. S., Jang, S. H., Han, S. J., Kim, H. S., ... Lee, S. H. Severe ARDS caused by adenovirus: early initiation of ECMO plus continuous renal replacement therapy. SpringerPlus 2016; 5(1):3571-9

9. Minhyeok L, Kim S, Kwon OJ, Ji Hye Kim, Inbeom Jeong, Ji Woong Son, Moon Jun Na, Yoo Sang Yoon, Hyun Woong Park, and Sun Jung Kwon. Treatment of Adenoviral Acute Respiratory Distress Syndrome Using Cidofovir With Extracorporeal Membrane Oxygenation: Case Series and Literature Review. Journal of Intensive Care Medicine 2017; 32 (3): 231-38. 